Research report

\title{
Characterization of gene-environment interactions by behavioral profiling of selectively bred rats: The effect of NMDA receptor inhibition and social isolation
}

\author{
Zita Petrovszki ${ }^{a}$, Gabor Adam $^{\mathrm{a}}$, Gabor Tuboly ${ }^{\mathrm{b}}$, Gabriella Kekesi $^{\mathrm{a}}$, Gyorgy Benedek ${ }^{\mathrm{a}}$, \\ Szabolcs Keri ${ }^{a}$, Gyongyi Horvath ${ }^{\mathrm{a}, *}$ \\ a Department of Physiology, Faculty of Medicine, University of Szeged, P.O. Box 427, H-6701 Szeged, Hungary \\ ${ }^{\mathrm{b}}$ Department of Neurology, Faculty of Medicine, University of Szeged, P.O. Box 427, H-6701 Szeged, Hungary
}

\section{H I G H L I G H T S}

- Characterization of selectively bred rats in terms of schizophrenia-related alterations.

- Complex treatment with social isolation and ketamine injections.

- Both pain sensitivity and motor activity decreased in treated animals.

- Sensory gating deficit and memory dysfunctions could also be observed.

- Selective breeding and complex treatment are important in producing these changes.

\section{A R T I C L E I N F O}

\section{Article history:}

Received 26 September 2012

Received in revised form

16 November 2012

Accepted 18 November 2012

Available online 27 November 2012

\section{Keywords:}

Memory

Motor behavior

Pain

Prepulse inhibition

Schizophrenia

Selective breeding

\begin{abstract}
A B S T R A C T
Gene-environment interactions have an important role in the development of psychiatric disorders. To generate and validate a new substrain of rats with signs related to schizophrenia, we used selective breeding after postweaning social isolation and chronic ketamine treatment through several generations of animals and compared the subsequent strain to naive rats that were not genetically manipulated. We further investigated whether social isolation and ketamine treatment augmented the appearance of schizophrenic-like signs in these rats. Four experimental groups were studied ( $n=6-15$ rats/group): naive rats without any treatment (NaNo); naive rats with postweaning social isolation and ketamine treatment (NaTr); 15th generation of selectively bred animals without any treatment (SelNo) or selectively bred rats with both isolation and ketamine treatment (SelTr). The startle reaction, tail-flick and novel object recognition tests were used to classify the animals into low- or high-risk for schizophrenia. Reduced pain sensitivity, higher degree of the startle reaction, disturbed prepulse inhibition, altered motor activity and decreased differentiation index in the memory test were observed in the 15th generation of the substrain, along with enhanced grooming behavior. Five functional indices (TF latency, startle reaction, prepulse inhibition, differentiation index, and grooming activity) were rated from 0 to 2 , and the analysis of the summarized score revealed that the NaNo group had the lowest overall indication of schizophreniclike signs, while the SelTr animals scored the highest, suggesting that both heritable and environmental factors were important in the generation of the behavioral alterations. We assume that further breeding after this complex treatment may lead to a valid and reliable animal model of schizophrenia.
\end{abstract}

(C) 2012 Elsevier B.V. All rights reserved.

\section{Introduction}

Schizophrenia is a devastating psychiatric disorder that impairs mental and social function and affects approximately $1 \%$ of the population worldwide [1,2]. It is characterized by positive symptoms (hallucinations, delusions, and thought disorder), negative

\footnotetext{
* Corresponding author. Tel.: +36 62544 971; fax: +36 62545842 .

E-mail address: horvath.gyongyi@med.u-szeged.hu (G. Horvath).
}

symptoms (deficits in social interaction, emotional expression, and motivation), and cognitive dysfunction (impaired attention/information processing, problem-solving, processing speed, verbal and visual learning and memory). Schizophrenia is considered as a complex, multifactorial disease. It is clear that susceptibility is hereditary, in some cases; however, none of the identified risk genes are specific to schizophrenia but rather indicate a general vulnerability to mental health disorders [3]. The neurodevelopmental hypothesis of schizophrenia is also a major theory which suggests the significance of different stressors in 
the etiology of this disease [4,5]. Dopaminergic, serotoninergic, glutamatergic and GABAergic deficits have been proposed as pathophysiological factors in schizophrenia. The underlying process of the disease occurs in the early stages of neurodevelopment and manifests only later, during the developmental restructuring of the central nervous system.

In order to understand the biological mechanisms underlying a complex disorder like schizophrenia, and in search of novel drug targets, valid animal models are necessary. There are four main groups of chronic animal models for schizophrenia: pharmacological-, lesion-, environmental- and genetic models, and a few studies applied certain combinations of these [6-9]. It is wellknown that NMDA antagonists worsen symptoms in schizophrenia and can induce schizophrenia-like symptoms in normal individuals [10-12]. Animals treated with NMDA receptor antagonists exhibit a number of changes related to schizophrenia, including deficits in memory function, pain sensitivity, as well as hyperresponsiveness to stimulants such as amphetamine [6,13-17]. The NMDA receptor system has an effect on several transmitter systems in the cortico-limbic-striatal network, and also plays a crucial role in brain plasticity during early development $[13,15,18]$; therefore, the developing brain is more susceptible to a chronic, low-dose blockade of NMDA receptors: it causes synaptic weakening and elimination by over-pruning in several brain regions, including the prefrontal cortex and the hippocampus [19-25].

The profound neurobiological effects of stress are believed to be the basis of many neuropsychiatric changes. Since Hatch and colleagues first reported behavioral abnormalities in socially isolated rats [26], a large body of evidence has accumulated to suggest that postweaning social isolation has profound, long-term effects on rodent brain and behavior. Thus, postweaning social isolation is an alternative, non-pharmacological model that produces a number of behavioral consequences in adulthood that are similar to schizophrenia symptoms, including deficits in sensorimotor gating, pain sensitivity, motor activity and enhanced sensitivity to psychoactive drugs [27-32]. This intervention also causes specific deficits in the prefrontal cortex, significant neurotransmission abnormalities including enhanced dopamine and serotonin functions in the basal ganglia $[8,33,34]$.

As the subchronic NMDA-receptor antagonist model and the postweaning social isolation model of schizophrenic symptoms produce somewhat complementary, but not always robust behavioral alterations, some authors applied a combined "double hit" model to investigate the hypothesis that these manipulations can enhance the reliability of the schizophrenia model $[35,36]$. This paradigm applied in adult or juvenile rats induced several behavioral abnormalities, such as hyperresponsiveness to different stress situations, drugs and altered pain sensitivity $[6,15,32,37,38]$. Importantly, combining the two manipulations did not produce detectable additive or synergistic effects on behavior or hippocampal plasticity, however, these animals showed more schizophrenia-like signs.

Animal models generated by artificial selection are tools that can be used to gain a better understanding of the genetic makeup behind the complex symptomatology of different syndromes including schizophrenia [39-41]. There are data to suggest that selective breeding approaches in rats may be a powerful strategy to unravel the genetic basis of schizophrenia $[40,42,43]$.

We hypothesized that the combination of genetic and environmental factors could yield a reliable rat model of schizophrenia; thus, the aim of our study was to generate and validate a new substrain of rats by selective breeding after social isolation and chronic ketamine (which acts primarily as a noncompetitive NMDA receptor antagonist) treatment. Selective breeding started in March 2008 , and the desired substrain was defined as exhibiting measurable alterations in acute heat-pain sensitivity, sensory gating and memory functions. The behavioral profile (sensory gating, pain sensitivity, memory function) was characterized in the 15th generation of our substrain by using the tail-flick (TF), the prepulse inhibition (PPI) and novel object recognition (NOR) tests.

\section{Materials and methods}

\subsection{Selective breeding process}

All procedures were ethically approved by the institutional animal care committee. Both male and female Wistar rats were used. Starting from a population of outbred Wistar rats ('parental generation': 10 males and 10 females), a breeding line was established by selective breeding according to the rats sensitivity to acute heat pain after social isolation and ketamine treatment. In further generations, the parental generation consisted of between 13 and 16 animals of each sex. The paradigm for selective breeding through several generations was as follows: rats, after weaning at 3 weeks of age (21-23 days), were tested with the TF test and then housed individually for 28 days (between 4 and 7 weeks of age) in cages of $42 \times 15 \times 12 \mathrm{~cm}(1 \times \mathrm{w} \times \mathrm{h})$ with wood shavings as bedding and nesting material. The animal housing rooms, as well as the experimental rooms, were kept under standard laboratory conditions (light-dark circle: $12: 12 \mathrm{~h}$; light on at $06: 00 \mathrm{~h}$; temperature $22 \pm 1{ }^{\circ} \mathrm{C}$; relative humidity: $55 \pm 10 \%$ ). Commercial rat diet and bottled tap water were available ad libitum. The cages were placed in shared racks so that auditory and olfactory contacts were maintained. The animals were treated with ketamine (CALYPSOL, Richter Gedeon Nyrt., Budapest, Hungary; $30 \mathrm{mg} / \mathrm{kg}$ intraperitoneally, $4 \mathrm{ml} / 1000 \mathrm{~g}$ body weight, daily, 5 times/week, 15 injections in total) from 5 to 7 weeks of age. Duration of ketamine treatment and isolation parameters were adapted from earlier studies $[6,15,44]$. At the end of the treatment, animals were re-housed in a group setting (4-5 rats per cage) and 1 week of recovery, with no treatment, followed. Behavioral assessment started at the age of 9 weeks with the TF test. Five rats of both sexes, that showed the highest pain threshold, as indicated by the TF test, were selected for the next breeding generation. Their offspring (1st generation) and the subsequent 2 nd generation were also tested only in the TF test, and again 5 rats of each sex with the highest pain thresholds were chosen to parent the next generation of the breeding line. From the 3rd generation we also used the PPI test to investigate sensory gating (at the age of 10 weeks), and the animals showing a high pain threshold, along with a low PPI were selected for a further breeding line. From the 6th generation, the NOR test was also applied (at the age of 11 weeks) to investigate memory functions and motor activity. Thus, animals with impaired pain sensitivity, PPI and NOR were selected for the further breeding lines. From the second generation, 5-7 animals of both sexes were selected for breeding. Sibling mating was avoided by paying close attention to the litter of origin, and the litter size was reduced to a maximum of 6-8 pups (the number of males and females was approximately equal), ensuring that each family contributed equally to the next generation. We found no signs of inbreeding depression (i.e. reduction of fertility, deformed offspring, small litters, poor mothering ability) in the selected line. Male rats of the 15 th generation were involved in the present experiment.

\subsection{Experimental paradigm}

Four experimental groups of male rats were compared ( $n=6-15$ rats/group): naive socialized rats without any treatment ( $\mathrm{NaNo}$ ), or with isolation and ketamine treatment (NaTr) and 15th generation selectively bred animals without any treatment (SelNo), or with isolation and ketamine treatment (SelTr). Groups were matched according to body weight $(50 \pm 1.7 \mathrm{~g})$ and their TF values at the age of 3 weeks. The testing schedule is presented in Fig. 1 . The body weights of rats in all experimental groups were measured throughout the investigation period.

\subsection{Nociceptive testing}

Acute nociceptive threshold was assessed by the TF test. The reaction time was determined by immersing the distal $5 \mathrm{~cm}$ portion of the tail in hot water $\left(48^{\circ} \mathrm{C}\right)$ until a tail-withdrawal response was observed (cut-off time: $20 \mathrm{~s}$ or $40 \mathrm{~s}$ at the age of 3 or 9 weeks, respectively). TF latencies were obtained four times at $0,30,60$, and $90 \mathrm{~min}$ and, since they did not differ significantly, were averaged to establish the pain threshold for each group.

\subsection{Prepulse inhibition test}

PPI of the acoustic startle response was measured in four startle chambers as described previously [45]. The Plexiglas startle chamber was in a sound-attenuated room and was divided into four identical compartments $(12 \times 17 \times 15.3 \mathrm{~cm}$ each $)$. Noise bursts were applied through a speaker mounted close to the backside of the chamber. Under the cage, a piezoelectric accelerometer (i.e. force transducer) sensitive to rat startle-like movements produced an electrical signal that was amplified by a signal conditioner and visualized on a computer screen. Rats were allowed to habituate to the background noise $(70 \mathrm{~dB})$ for $10 \mathrm{~min}$, immediately thereafter they were exposed to three different trial types: a PULSE ALONE (PA) in which a $40 \mathrm{~ms}$ $95 \mathrm{~dB}$ white noise burst was presented; PREPULSE ALONE (PPA), $20 \mathrm{~ms} 76 \mathrm{~dB}$; and the 


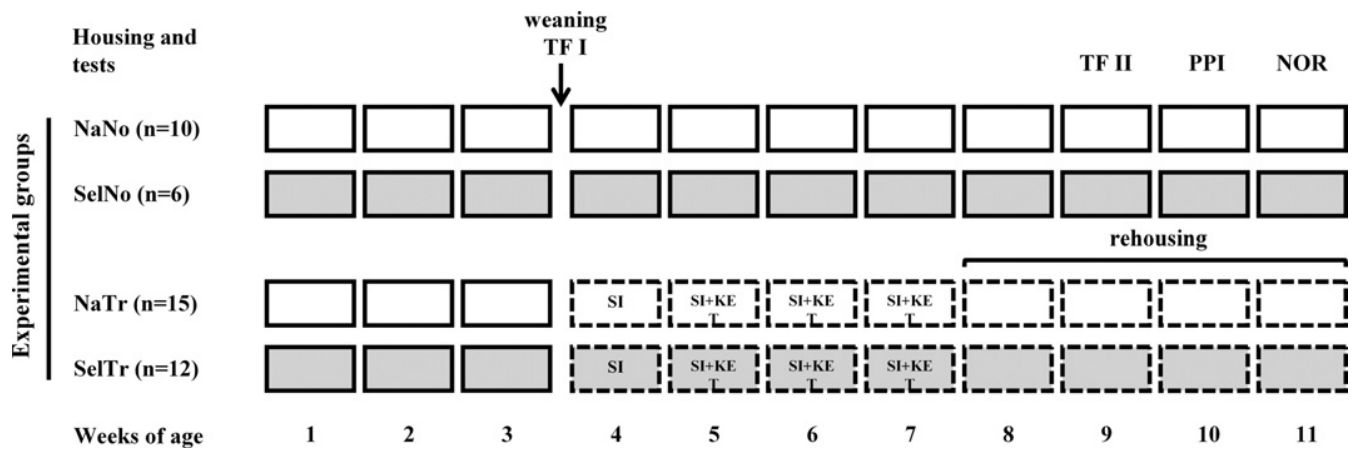

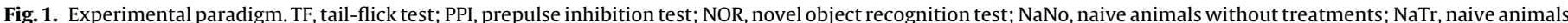

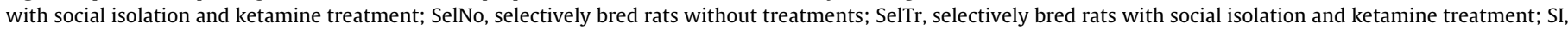
social isolation; KET, ketamine treatment.

PREPULSE-PULSE PAIR (PP) in which prepulse stimuli were followed by the acoustic startle stimulus with a latency of $150 \mathrm{~ms}$. All types were presented 10 times. The interstimulus intervals ranged from $7 \mathrm{~s}$ to $13 \mathrm{~s}$, and there was a $10 \mathrm{~min}$ ' resting period between each trial. The \%PPI values were calculated as percentages using the following formula: \%PPI = $[1-$ (startle response for PREPULSE + PULSE trial) $/($ startle response for PULSE ALONE trial)] $\times 100$. Since the startle reaction increases significantly with body weight, we normalized the reaction to body weight, accordingly:

Relative startle reaction : $\frac{\text { startle reaction } \times 100}{\text { body weight }(\mathrm{g})}$.

\subsection{Novel object recognition test}

Rats were habituated to the testing room (with dim light) for $60 \mathrm{~min}$ prior to the start of the experiments. The NOR test was conducted in a Plexiglas box (arena, $60 \times 34 \times 33 \mathrm{~cm}$ ) without bedding, with black walls to obscure the testing room from the animals. Toy brick towers (Lego Group, Billund, Denmark) of similar size but not exactly the same shape $(\sim 8 \times 2 \times 3 \mathrm{~cm})$ were used as test objects. They were affixed to the floor of the box to prevent them from being displaced during testing. The objects were placed $13 \mathrm{~cm}$ from the opposing corners of the arena, and the rat was consistently placed in the middle of the arena to be equidistant from both objects. Between the testing of different animals, the arena and the objects were cleansed with $70 \%$ ethanol.

\subsubsection{Procedures}

Habituation phase: Each rat was placed in the center of the chamber and allowed to explore the open field without any objects for a single 10-min session. Sample phase: One minute following the habituation session, the sample phase began. Two objects with the same size and shape (S1 and S2) were mounted in the open-field. Rats were put into the center of the open field again, and allowed to explore the two identical objects for $5 \mathrm{~min}$. Test phase: At the end of the sample phase, each rat was returned to their home cage for a one-hour retention interval, while one of the objects was replaced with another, visually non-identical one (N: novel). The other object (F: familiar) was the same as in the sample phase. Afterwards, a 5-min test phase followed.

Behavior in all trials was recorded with an infrared video device (WCM-21VF, $\mathrm{CNB}$, China). The scoring of the different behaviors was carried out by investigators blind to the applied treatment. The following parameters were scored in each phase: duration of stereotypic behaviors, such as rearing, self-grooming, the time of exploratory activity and walking. Object exploration was defined as animals' licking, sniffing or touching the object with the forepaws, but not leaning against, turning around, standing on or sitting on the object. Since the habituation phase lasted twice as long as the other phases, behavioral activity was divided into and scored in sub-phases (0-5 and 5-10 min) for analysis.

The discrimination index (DI) was calculated for both the sample and test phases as follows: DI: (time spent exploring $N$ vs S1 object-time spent exploring $F$ vs S2 object)/(total time spent exploring both the objects [S1 $+S 2]$ vs $[N+F])$. If the animals did not explore the objects during the sample or test phases, they were considered as non-responders and data from these animals were not included in the final analysis (altogether one animal from the SelTr group was excluded on such grounds).

\subsection{Statistical analyses}

Data are expressed as means + SEM. The median split method was used for transforming continuous variables into categorical ones. A quartile-based scoring method was used. The values in the first (lower) quartile received 0 points, values in the third (upper) quartile received a score of 2 , and the values between them received 1 point. Five aspects (TF latency at the age of 9 weeks, relative startle reaction, \%PPI, $\mathrm{DI}$, and grooming activity) were rated from 0 (lowest risk) to 2 (highest risk), and summarized to generate the total schizophrenia score, which ranged from 0 to 10 . Using this score, it was possible to classify animals as either low- or high-risk for schizophrenia using quartiles of the total schizophrenia score.

Effects of treatment (social isolation + ketamine) and strain (naive or selectively bred), and interactions were assessed using two-way ANOVA. Subsequent analysis was performed using the Fisher-LSD test. Level of significance was set at $p<0.05$. For the analyses, STATISTICA for Windows 7.1 (Statsoft Inc., Tulsa, OK) was used.

\section{Results}

The body weight measured on the different testing days (Fig. 2) showed a significant effect of time $\left(F_{3,117}=3077.81, p<0.0001\right)$ and strain $\left(F_{1,39}=24.78, p<0.001\right)$, and the interaction between time and strain $\left(F_{3,117}=7.13, p<0.001\right)$ was also significant. That is, the substrain started to exhibit a lower body weight from age of 9 weeks. The social isolation together with ketamine treatment did not result in further weight loss.

\subsection{Tail-flick test}

ANOVA revealed a significant effect of strain $\left(F_{1,39}=4.23\right.$, $p<0.05)$, time $\left(F_{1,39}=328.15 ; p<0.001\right)$ and a significant interaction between time and strain $\left(F_{1,39}=4.94 ; p<0.05\right)$ on the TF latencies measured at 3 and 9 weeks of age; thus, the TF latency significantly increased in all groups with time. Post hoc comparison did not reveal differences between the groups at the age of 3 weeks, but a tendency toward TF latency increase was observed in the new substrain (naive: $4.1 \pm 0.21 \mathrm{~s}$, 15 th generation: $4.6 \pm 0.27 \mathrm{~s})$.

Significant differences were observed at the age of 9 weeks between NaNo and both of the substrain groups (SelNo and SelTr), with these groups having the lowest pain sensitivity (Fig. 3). The latency in the NaTr group did not differ from any other group.

\subsection{Prepulse inhibition test}

ANOVA revealed a significant effect of prepulse stimulation $\left(F_{1,39}=72.47, p<0.0001\right)$, and strain $\left(F_{1,39}=6.50, p<0.05\right)$ (Fig. $\left.4 \mathrm{~A}\right)$ on the magnitude of the startle reaction. The response significantly decreased in the case of prepulse stimulation in all groups, except the SelNo group. The post hoc comparison revealed significant differences between the NaNo and SelTr groups with the PA, while both of the selectively bred groups showed a significantly higher degree of relative startle reaction compared to both of the naive groups with the PP. Regarding \%PPI, the effect of strain was significant $\left(F_{3,39}=5.59 ; p<0.005\right)$; thus, both groups of the substrain (SelNo and SelTr) had lower PPI compared to the naive groups (NaNo and NaTr) (Fig. 4B). 

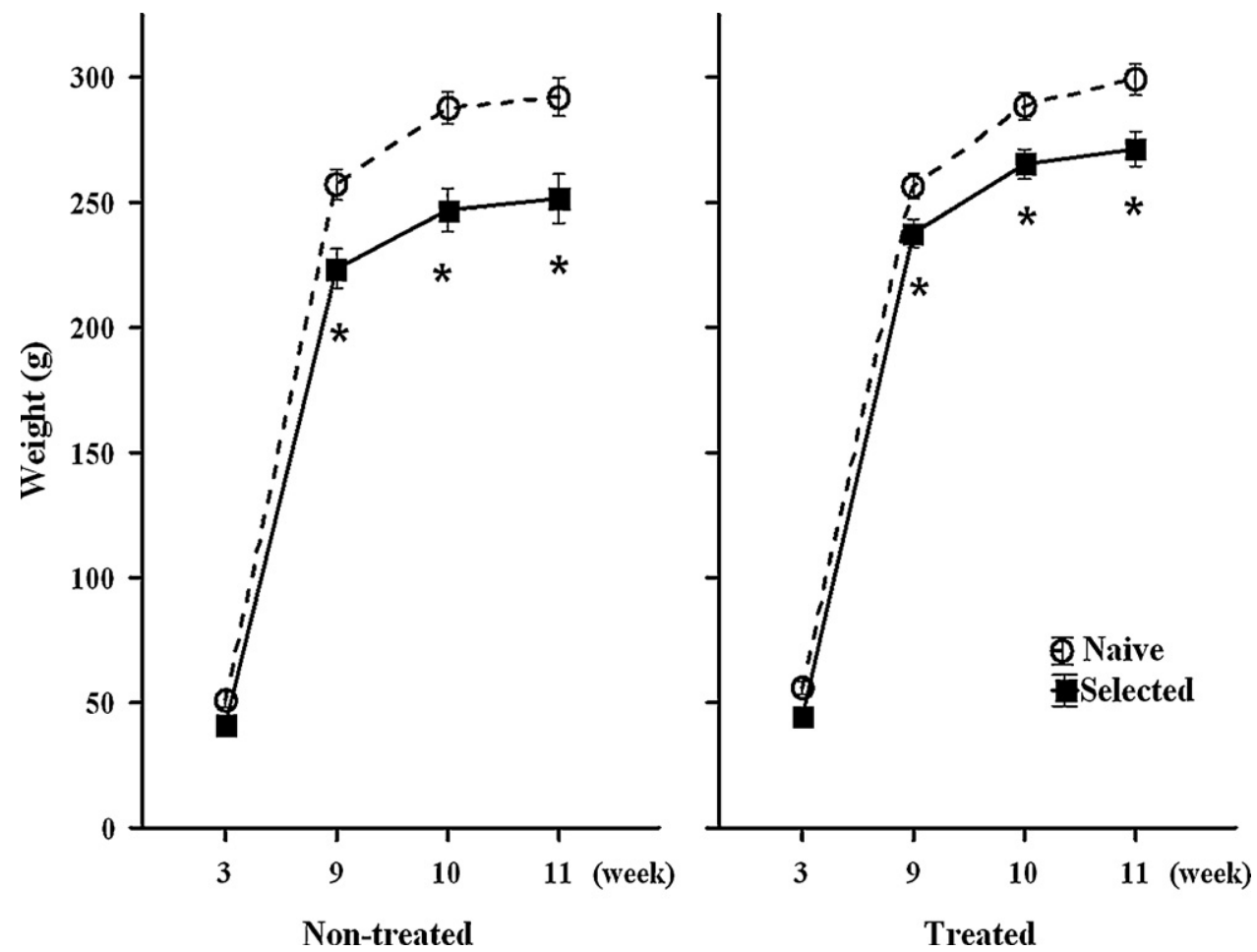

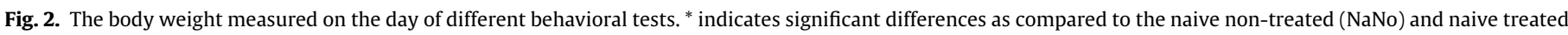
$(\mathrm{NaTr})$ groups. Data are expressed as means \pm SEM.

\subsection{Novel object recognition test}

ANOVA revealed a significant effect of strain $\left(F_{1,39}=6.75\right.$, $p<0.05)$, of phase $\left(F_{3,117}=27.35, p<=0.001\right)$, and significant interaction between phase and strain $\left(F_{3,117}=3.69, p<0.05\right)$ (Fig. 5A) on the rearing activity during the different phases of the NOR test. Rearing activity decreased with time (phase) in all groups, and the 15th generation showed lower rearing activity in the

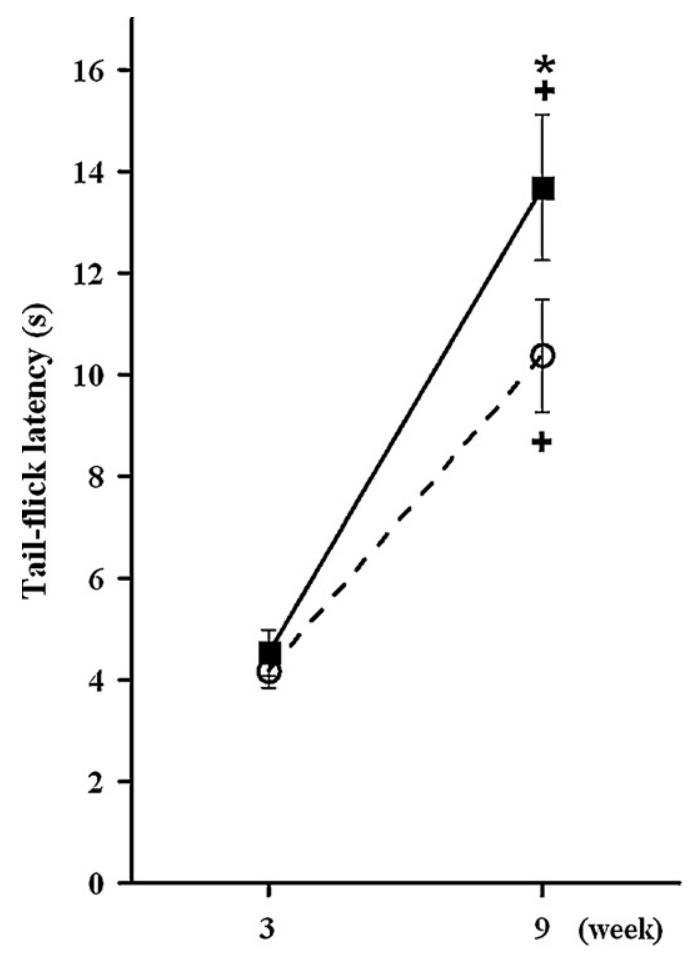

Non-treated

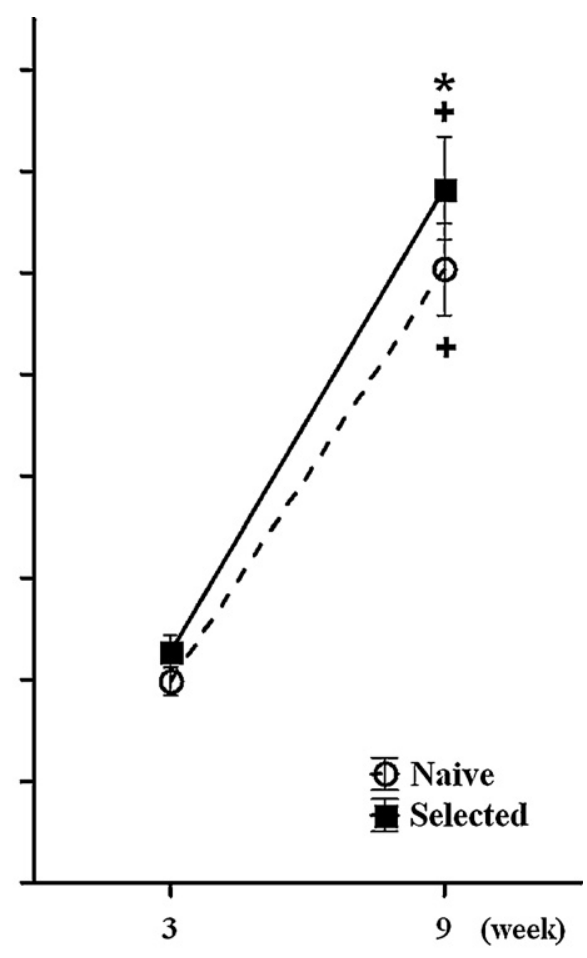

Treated

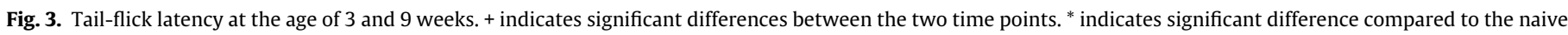
non-treated (NaNo) group. Data are expressed as means \pm SEM. 


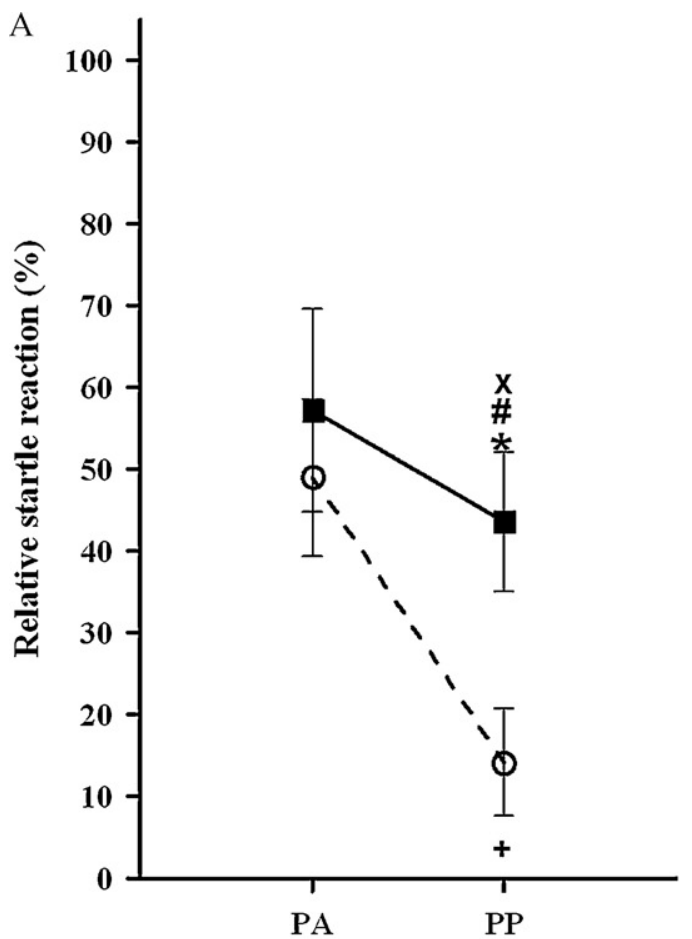

Non-treated

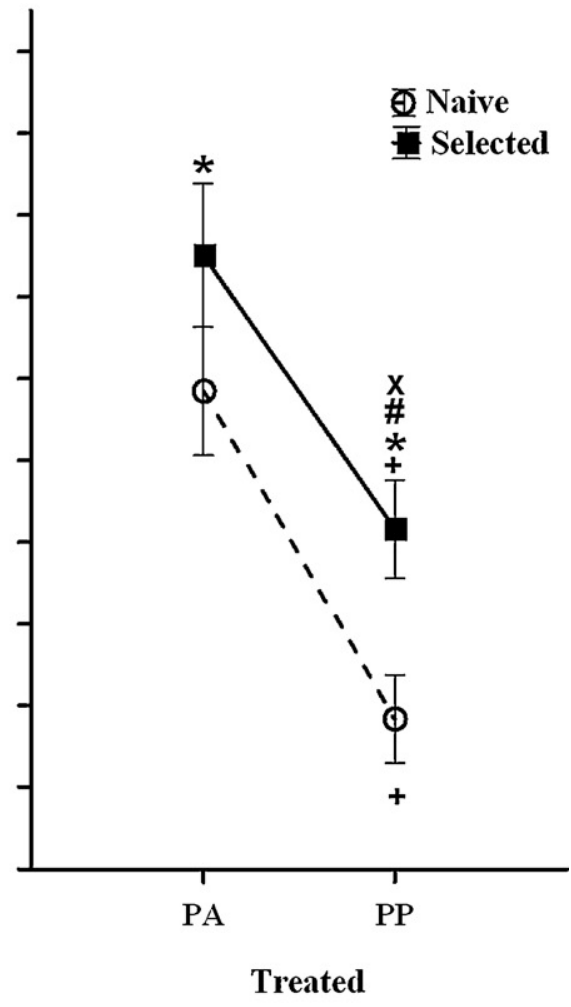

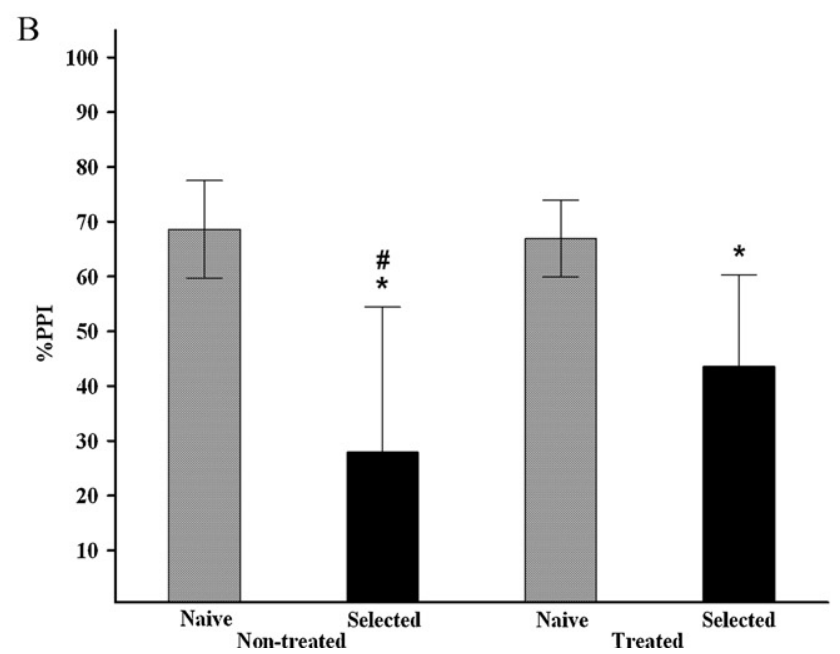

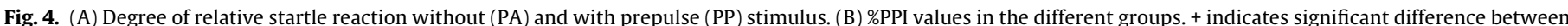
$\mathrm{PA}$ and $\mathrm{PP},{ }^{*}$ and \# indicate significant difference compared to the naive non-treated (NaNo) and treated (NaTr) groups, respectively. Data are expressed as means \pm SEM.

sample and/or testing phases. The NaTr group showed enhanced rearing activity in the test phase compared to all the other groups.

Strain differences were also found in the grooming behavior, i.e. the substrain showed increased grooming activity during the second part (5-10 min) of the habituation phase $\left(F_{1,39}=4.18, p<0.05\right.$; Fig. 5B).

Analysis of walking duration revealed a significant effect of strain $\left(F_{1,39}=8.88, p<0.01\right)$, phase $\left(F_{3,117}=56.61, p<0.001\right)$ and a phase-treatment interaction $\left(F_{3,117}=3.39, p<0.05\right)$; thus, walking activity decreased with time (phase), and was lower in the new substrain, while the NaTr group showed enhanced activity in the sample and test phases (Fig. 5C). Both NaTr and SelTr groups showed an increased exploring time of the objects (Fig. 5D). As for the DI, ANOVA revealed a significant effect of phase $\left(F_{1,38}=5.70\right.$, $p<0.05)$. The post hoc comparison revealed that in the NaNo group
DI was significantly enhanced in the presence of the new object, while this enhancement could not be observed in any other groups (Fig. 5E).

\subsection{Categorization}

Since the quality of motor activity significantly differed between the NaTr and SelTr groups, these parameters were not used for categorization. ANOVA revealed significant differences between the four groups $\left(F_{3,39}=9.47, p<0.001\right)$ in the summarized score, i.e. the NaNo group had the lowest score, while the SelTr group scored the highest (Fig. 6A). The histogram of the summarized score shows that all NaNo animals scored lower than 6 points, while in all of the other groups there were some animals that scored higher, and the highest ratio of these was observed in the SelTr group (Fig. 6B). 


\section{Discussion}

Schizophrenia poses a challenging degree of complexity with respect to genetic and environmental factors; nonetheless, only a few studies have addressed possible gene-environment interactions in the context of schizophrenia models [5,46,47]. We combined selective breeding, postweaning social isolation and subchronic NMDA antagonist treatment to determine the effects of these interventions on responses to acoustic stimulation, memory function, pain sensitivity and motor activity; the parameters
A

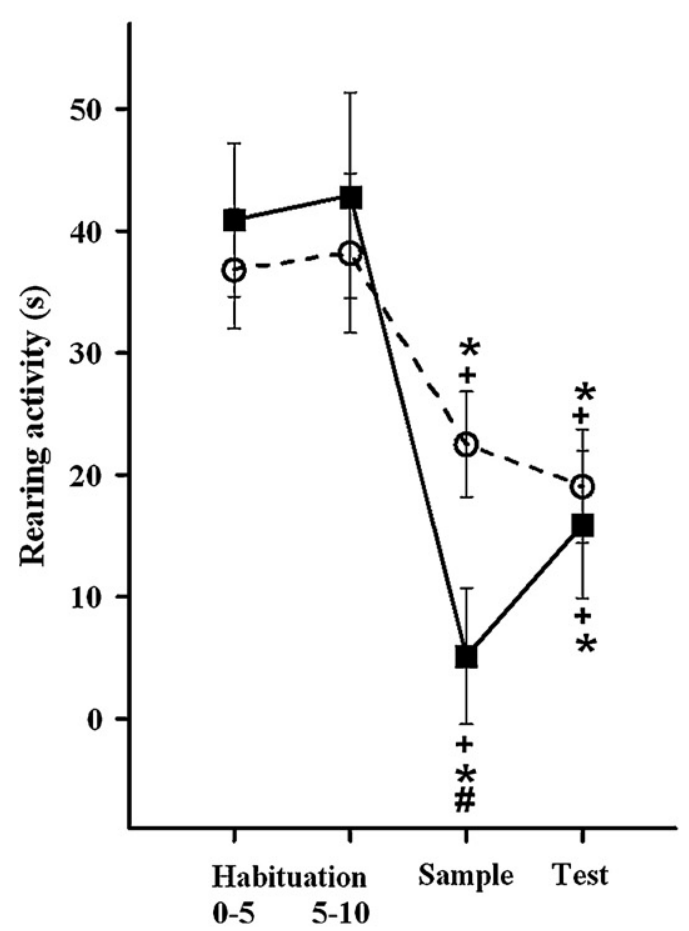

B

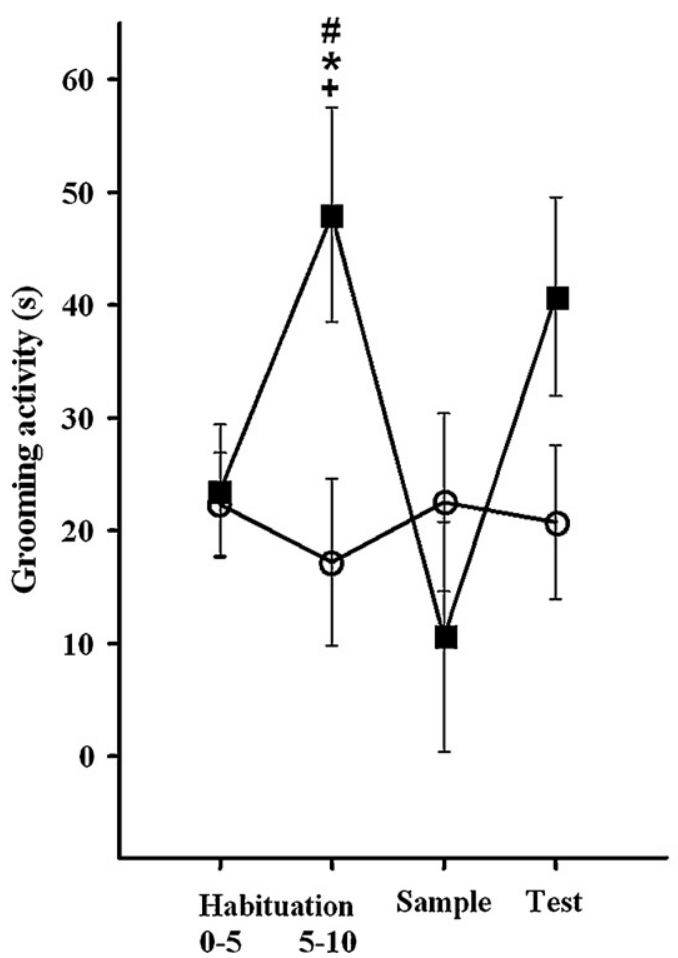

Treated

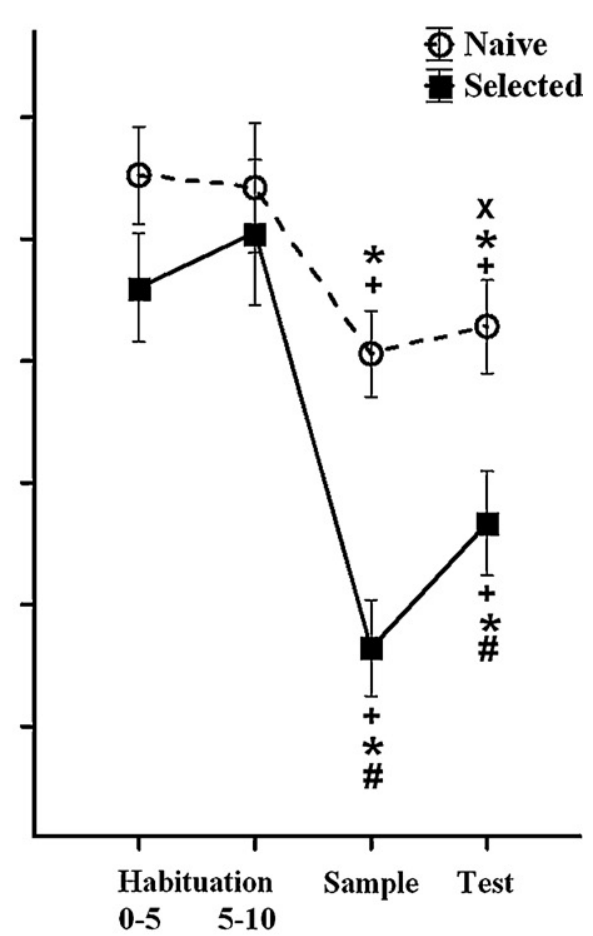

\section{Treated}

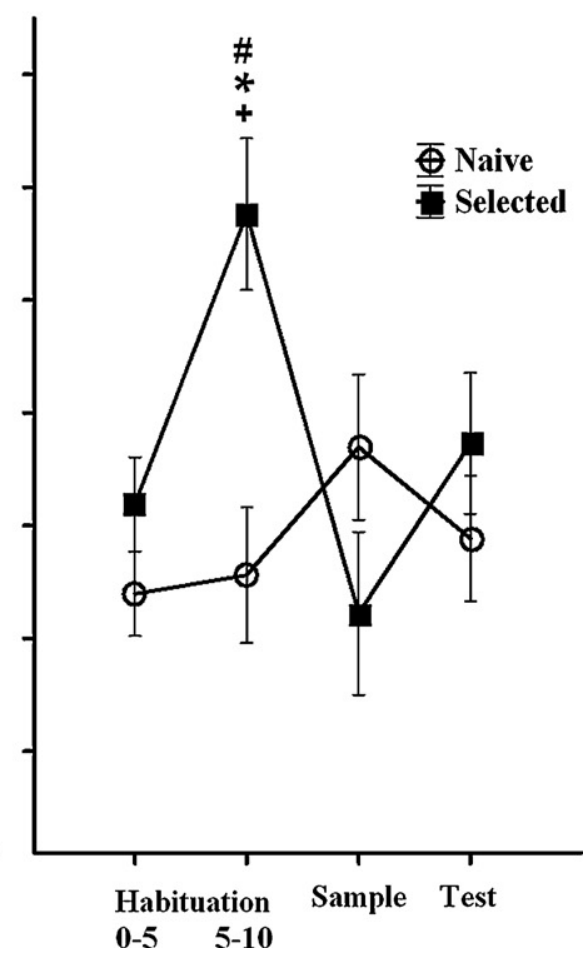

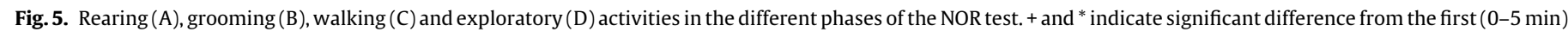

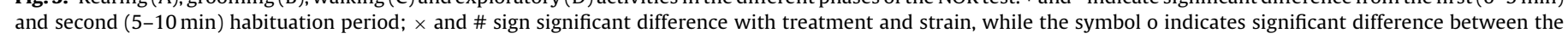

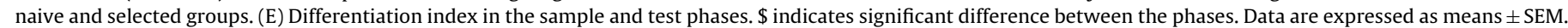


$\mathrm{C}$

\section{Non-treated}

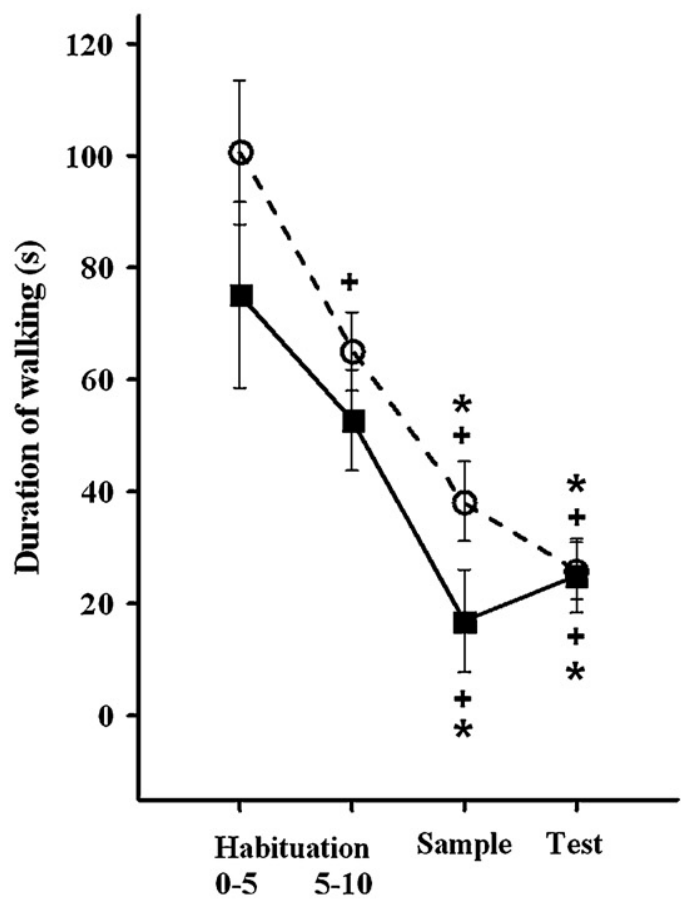

Treated

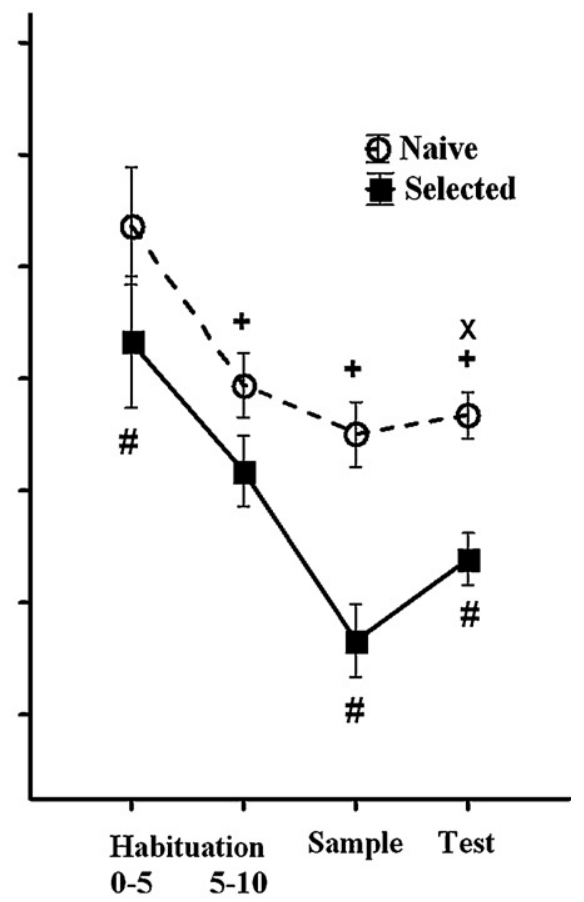

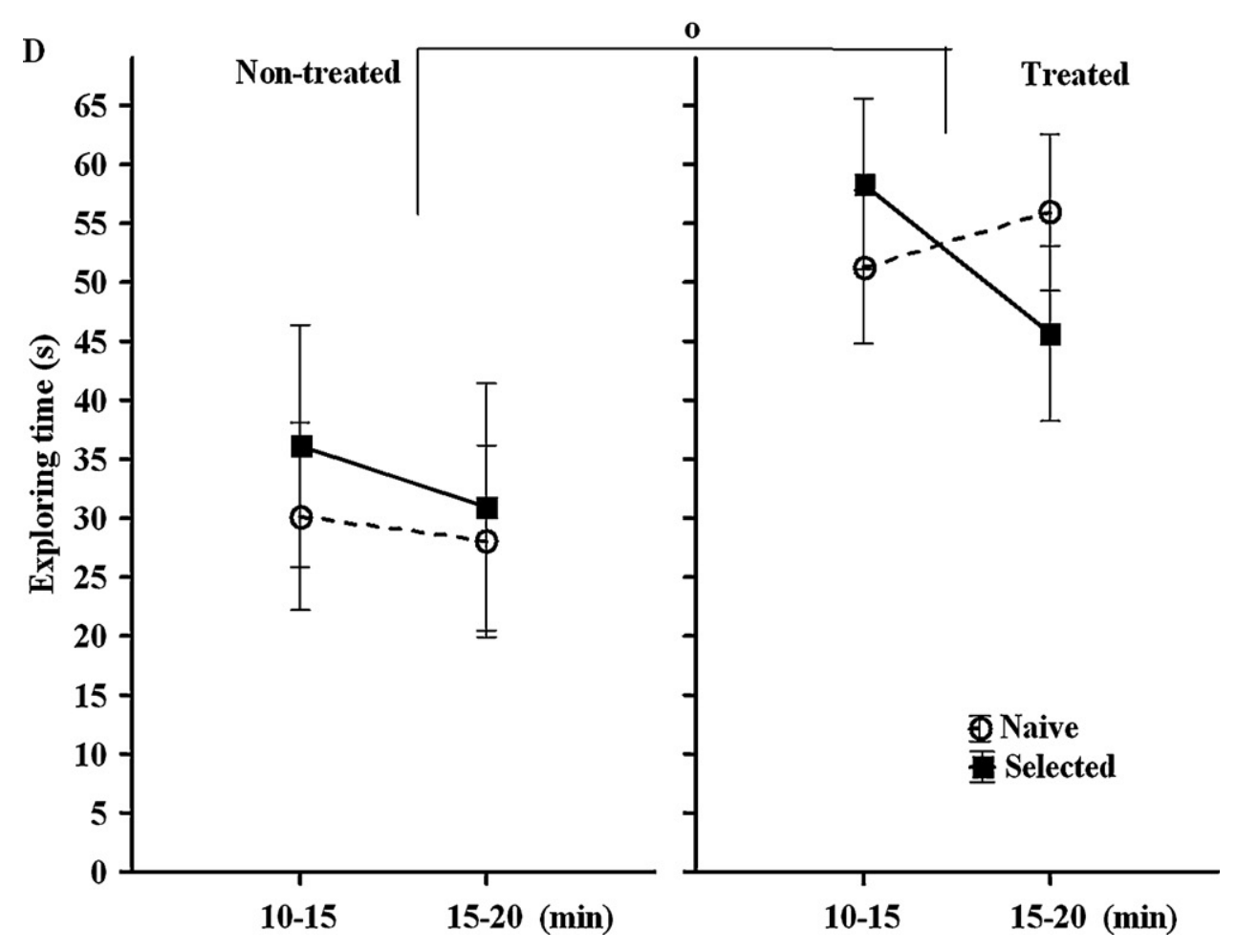

Fig. 5. (Continued)

that are impaired in several neuropsychiatric disorders, like schizophrenia. Our data suggest that this complex paradigm can lead to an improved model of schizophrenia; although, further breeding is required to enhance its reliability.

\subsection{Sensory gating}

Deficits in sensory gating have been described as a prominent area of information processing dysfunction in individuals with psychosis, and it may contribute to the characteristic thought disorder and cognitive fragmentation seen in schizophrenia [11,48-51]. It is important to mention that PPI deficits are not unique to schizophrenia, as patients with other neuro-psychiatric diseases (e.g. Huntingtons's disease, Tourette's syndrome, autism, bipolar or panic disorder) also show this disturbance, and a lack of this phenomenon in schizophrenia has also been reported [50,52].

Previous studies revealed that repeated NMDA-antagonist treatment of neonatal or adult rats led to the disruption of PPI 
$\mathbf{E}$ Non-treated

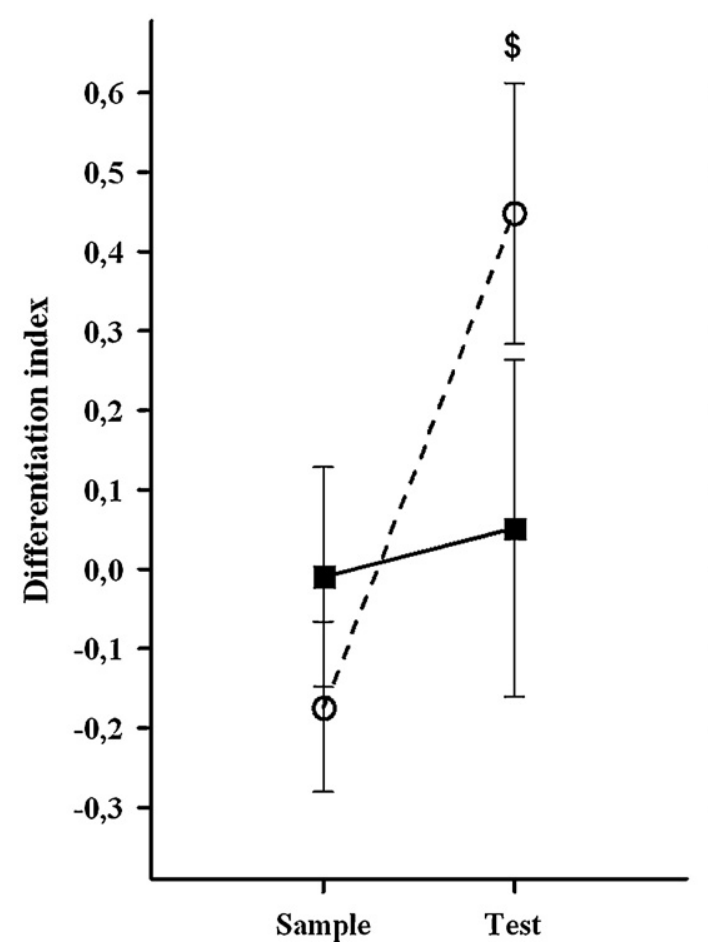

Treated

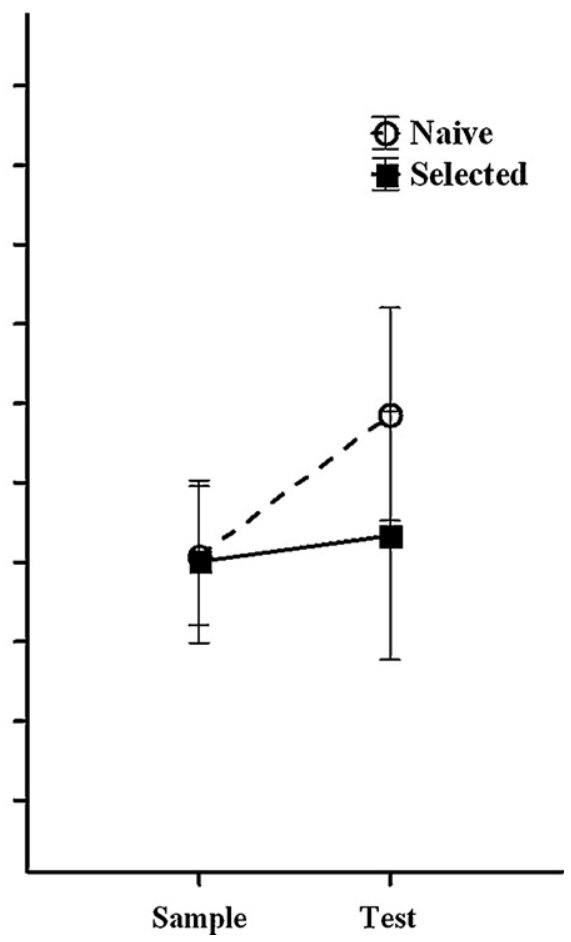

Fig. 5. (Continued).

in some but not all the animals [53-56], and the cessation of NMDA-antagonist treatment resulted in remission; which, suggests that this treatment by itself is not sufficient to produce a long-term simulation of the PPI disturbance [17,57-59]. Plenty of evidence suggests that long-term postweaning social isolation may also cause impaired PPI in rodents, but resocialization may lead to recovery in these changes; however, the data are somewhat inconsistent [11,60-69]. It is assumed that changes in the prefrontal cortex after social isolation and/or imbalances between neural connections within the cortico-striato-limbic circuitry lead to the observed PPI disturbances [8]. Altered sensitivity to novelty and disturbed PPI as a result of selective breeding was proven to be heritable, and this can be used to develop an animal model for schizophrenia [43,70-73]. The rats with impaired PPI also exhibited deteriorated social behavior, impaired reward responses, and abnormalities in information processing; which indicates that rats with low PPI show other schizophrenia-like disturbances, as well. Regarding the combination of genetic manipulation with environmental factors, it has been shown that postweaning social isolation for 12 weeks did not impair PPI in Nurr1 wild type mice, but it was disturbed in heterozygotic animals [74].

We did not find a striking effect of social isolation and ketamine treatment on PPI after two weeks of treatment cessation in naive animals. Selective breeding was effective, but the combination of these interventions did not lead to further impairment; which suggests that genetic factors played the major role in the development of PPI disturbance.

\subsection{Memory}

Cognition, including memory, is impaired in schizophrenia, and both social deprivation and repeated treatment with NMDA antagonists of juvenile animals can disrupt memory functions which are related primarily to the prefrontal cortex [13,75-80]; however, several studies failed to induce impairments in tests of memory with these treatments, or only modest learning disturbances were observed $[13,17,20,21,52,55,56,78-82]$. Ashby et al. investigated the effects of subchronic NMDA-antagonist, MK-801, and postweaning social isolation (for 5 weeks) on hippocampal long term potentiation (LTP) after a 7 days' washout period [36]. While subchronic MK-801 treatment enhanced hippocampal LTP, postweaning social isolation did not influence it, and the combination of the two manipulations did not result in detectable additive or synergistic effects on hippocampal plasticity.

The NOR task is based on the spontaneous novel object preference of rodents. A reduction in novel object recognition might be interpreted as a memory deficit, and the underlying process is a possible analog of declarative memory in humans [83-85]. Anatomically, this task is assumed to depend on the hippocampus, the nigrostriatal dopaminergic pathway and rhinal cortex [86,87]. Both postweaning isolation and NMDA antagonist treatment can lead to impairment in the NOR test, but the results are controversial in this respect, too $[19,66,79,88-92]$.

We have found that all the groups, except for NaNo, showed impairment in the NOR test, i.e. the ability to discriminate between novel and familiar objects was disturbed; thus, we assume that both genetic and environmental factors play a role in the memory deficit. However, it would be useful to apply further memory tests (e.g. T-maze or holeboard) to characterize this deficit in detail.

\subsection{Motor activity}

Altered motor activity has been reported in schizophrenia. Depending on the disease subtype, psychopathology and medication, excessive motor agitation, reduced motor activity, even akinetic episodes, are observed, and these motor disturbances have been related to basal ganglia dysfunction [93-98]. Postweaning social isolation increases activity in novel environments, but data are controversial and the effect depends on the strain of rodents [62-64,66,89,90,99-103]. Most studies investigated motor 


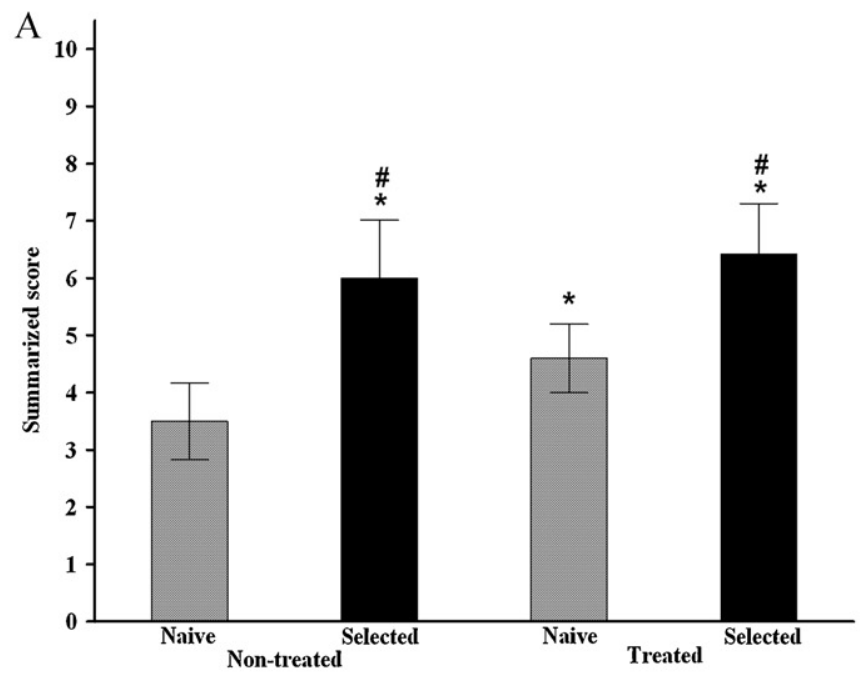

B
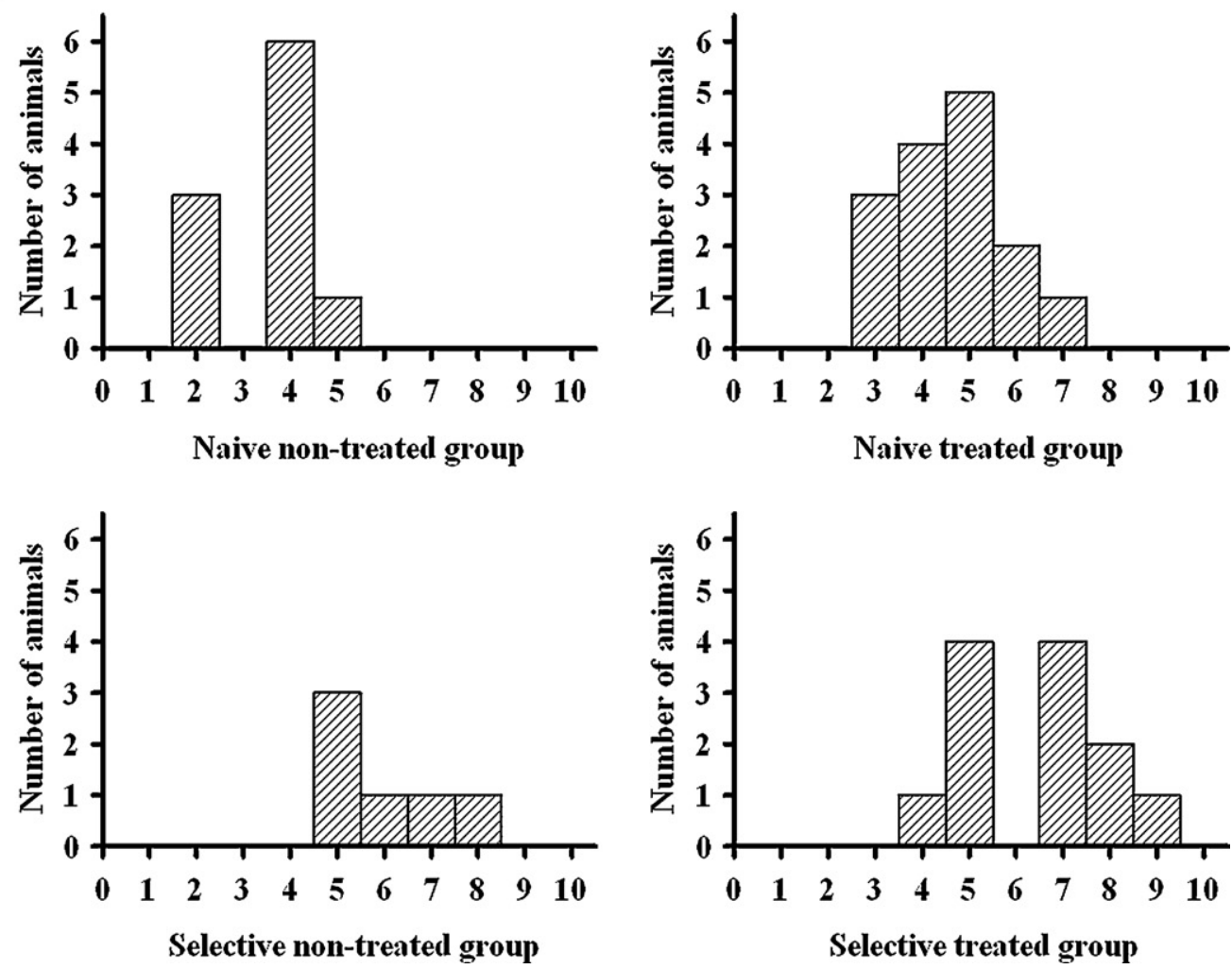

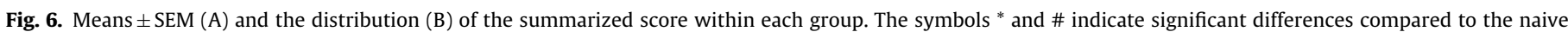
non-treated (NaNo) and treated ( $\mathrm{NaTr})$ groups, respectively.

activity during isolation, but social isolation by itself did not produce long-term changes in motor activity [60,104]. Some reports suggest motor disturbances after NMDA antagonist treatment, but the results are inconsistent, and the effect depends on the age of the animals $[19,82,91]$. Cessation of treatment in adult or juvenile rodents did not cause gross changes in motor activity, while early postnatal treatment was effective in this respect $[19,21,56,105]$. Beninger's laboratory investigated the effects of subchronic MK-801 and postweaning social isolation on motor activity $[35,36,106]$. Postweaning social isolation enhanced locomotor activity, while MK-801 treatment, alone, did not alter it, but blunted the amphetamine-induced hyperlocomotion. The combination of the two manipulations did not produce detectable additive or synergistic effects on behavior.
In the present study, the complex analysis of motor activity during the NOR test revealed that the selective breeding decreased overall motor activity but increased the grooming behavior. The ketamine treatment + social isolation induced increased exploratory activity in both naive and selected groups. Interestingly, the complex treatment in selectively bred animals resulted in an altered motor phenotype with decreased rearing and walking activity, accompanied by increased exploratory and grooming activities. The enhanced grooming behavior can indicate anxiety, and might present a useful strategy to investigate stress-related responses in animal models of neuropsychiatric disorders [107-109]. Hyper-exploratory activity was also observed in animals with hippocampal lesions, which is another model for schizophrenia [110]. To clarify these results regarding the different 
aspects of motor behavior, further investigation of motor behavior is necessary in these animals.

\subsection{Pain sensitivity}

Clinical reports pointed out that many patients with schizophrenia are less sensitive to pain than other individuals, and this is likely associated with increased morbidity and mortality [111-113]. Data are available to suggest that juvenile isolation causes significant changes in pain sensitivity, which might be due, at least partially, to changes in the number and activity of opioid receptors; suggesting a high importance of housing conditions in schizophrenia models [6,15,29,38,104,114-117]. Subchronic ketamine treatment and subsequent social isolation in adult rats produces slight changes in pain sensitivity [38]. Our recent study demonstrated that juvenile isolation, but not ketamine treatment, attenuated responses evoked by acute heat stimuli; while the combination of the two manipulations did not result in a further increase in TF latency. In the same study we showed that social isolation, ketamine treatment and their combination enhanced the antinociceptive effect of morphine [6]. While selective breeding led to a significant increase in pain threshold, the complex treatment applied in the present study did not result in a further enhancement; suggesting that genetic factors played a larger role in this effect.

It should be noted that our study is not without limitations. Although we did observe deficits persisting for weeks after the last drug administration, further studies are needed to determine whether these deficits are maintained over a longer time period following treatment cessation. It is well-known that no neuropsychological test is a perfect indicator of psychiatric disorder and indication of disease must be present on a battery of tests in order to justify a diagnosis of schizophrenia [118]. In animals, it is impossible to determine most of these parameters; therefore, other appropriate parameters must be chosen to indicate schizophrenia in rodents. While none of the measured parameters are specific to schizophrenia, we hypothesize that categorization and the cluster sampling of the described parameters could improve the model, as the presence of many of the described indicators together can suggest psychotic-like disturbance.

We support that this new substrain is a promising model for schizophrenia, but acknowledge that further complex environmental and genetic manipulations should be investigated to improve the model. Social isolation together with pharmacological treatment can increase the prevalence of the animals with schizophrenic signs, and the reliability of the model. Our present results confirm that selective breeding is still one of the most fundamental and effective methods for the assessment of complex traits influenced by multiple genes. A classic example of such complexity is the demonstration of cognitive abilities that show a significant inheritance, as indicated by the experiments of Tryon (1929) in selectively bred rats $[119,120]$. In the largest published familial schizophrenia cohort, Toulopoulou et al. demonstrated that a major portion of phenotypic correlation between schizophrenia patients in certain cognitive measures could be explained by shared multiple genes [121]. In spite of these facts, selective breeding is a relatively rare method used in schizophrenia research. Although many of the measures we used did not indicate a straightforward gene-environment interaction, the summarized score based on categorization revealed that the selectively-bred and treated animals differed most markedly from the naive, non-treated rats. This suggests that genetically pre-disposed traits together with environmental risk factors resulted in the most prominent impairment relative to naive animals with no environmental perturbation. A further limitation of our assessment of gene-environment interaction was that we used a limited set of tests. A more comprehensive battery of behavioral measures may lead to a better detection of such interactions.

In conclusion, selective breeding after juvenile isolation and ketamine treatment produces several signs which resemble those found in schizophrenia; however, further breeding is required to improve our animal model. Molecular biological studies are also required to reveal any changes of various neurotransmitter systems and genetic abnormalities. We suggest that the resulting rat line may serve as a potentially powerful model for the examination of the gene-environment interaction in the development of schizophrenia.

\section{Acknowledgments}

This work was supported by a Hungarian Research Grants (OTKA, K83810, NF72488; TAMOP 4.2.2.-08/01-2008-0002). The authors wish to thank Agnes Tandari for her technical assistance. The authors are grateful to Clark D.L. and Braunitzer G. for linguistic correction of the manuscript.

\section{References}

[1] Rossler W, Joachim Salize H, van Os J, Riecher-Rossler A. Size of burden of schizophrenia and psychotic disorders. European Neuropsychopharmacology 2005;15:399-409.

[2] Insel TR. Rethinking schizophrenia. Nature 2010;468:187-93.

[3] Cohen-Woods S, Schosser A, McGuffin P. From age correction to genome-wide association. Acta Psychiatrica Scandinavica 2009;120:355-62.

[4] Ayhan Y, Sawa A, Ross CA, Pletnikov MV. Animal models of gene-environment interactions in schizophrenia. Behavioural Brain Research 2009;204:274-81.

[5] Nagai T, Ibi D, Yamada K. Animal model for schizophrenia that reflects gene-environment interactions. Biological and Pharmaceutical Bulletin 2011;34:1364-8.

[6] Tuboly G, Benedek G, Horvath G. Selective disturbance of pain sensitivity after social isolation. Physiology and Behavior 2009;96:18-22.

[7] Chen J, Lipska BK, Weinberger DR. Genetic mouse models of schizophrenia: from hypothesis-based to susceptibility gene-based models. Biological Psychiatry 2006;59:1180-8.

[8] Weiss IC, Feldon J. Environmental animal models for sensorimotor gating deficiencies in schizophrenia: a review. Psychopharmacology 2001;156:305-26.

[9] Arranz MJ, de Leon J. Pharmacogenetics and pharmacogenomics of schizophrenia: a review of last decade of research. Molecular Psychiatry 2007; $12: 707-47$.

[10] Linn GS, O'Keeffe RT, Schroeder CE, Lifshitz K, Javitt DC. Behavioral effects of chronic phencyclidine in monkeys. NeuroReport 1999;10:2789-93.

[11] Geyer MA, Krebs-Thomson K, Braff DL, Swerdlow NR. Pharmacological studies of prepulse inhibition models of sensorimotor gating deficits in schizophrenia: a decade in review. Psychopharmacology 2001;156:117-54.

[12] Swerdlow NR, Geyer MA, Shoemaker JM, Light GA, Braff DL, Stevens KE, et al. Convergence and divergence in the neurochemical regulation of prepulse inhibition of startle and $\mathrm{N} 40$ suppression in rats. Neuropsychopharmacology 2006;31:506-15.

[13] Jentsch JD, Roth RH. The neuropsychopharmacology of phencyclidine: from NMDA receptor hypofunction to the dopamine hypothesis of schizophrenia. Neuropsychopharmacology 1999;20:201-25.

[14] McLean SL, Woolley ML, Neill JC. Effects of subchronic phencyclidine on behaviour of female rats on the elevated plus maze and open field. Journal of Psychopharmacology 2009:1-4.

[15] Kekesi O, Tuboly G, Szucs M, Birkas E, Morvay Z, Benedek G, et al. Longlasting, distinct changes in central opioid receptor and urinary bladder functions in models of schizophrenia in rats. European Journal of Pharmacology 2011;661:35-41.

[16] Wong AHC, Van Tol HHM. Schizophrenia: from phenomenology to neurobiology. Neuroscience and Biobehavioral Reviews 2003;27:269-306.

[17] Egerton A, Reid L, McGregor S, Cochran SM, Morris BJ, Pratt JA. Subchronic and chronic PCP treatment produces temporally distinct deficits in attentional set shifting and prepulse inhibition in rats. Psychopharmacology 2008;198:37-49.

[18] Breese GR, Knapp DJ, Moy SS. Integrative role for serotonergic and glutamatergic receptor mechanisms in the action of NMDA antagonists: potential relationships to antipsychotic drug actions on NMDA antagonist responsiveness. Neuroscience and Biobehavioral Reviews 2002;26:441-55.

[19] Li JT, Su YA, Guo CM, Feng Y, Yang Y, Huang RH, et al. Persisting cognitive deficits induced by low-dose, subchronic treatment with MK-801 in adolescent rats. European Journal of Pharmacology 2011;652:65-72.

[20] Nemeth H, Varga H, Farkas T, Kis Z, Vecsei L, Horvath S, et al. Long-term effects of neonatal MK-801 treatment on spatial learning and cortical plasticity in adult rats. Psychopharmacology 2002;160:1-8. 
[21] Kawabe K, Iwasaki T, Ichitani Y. Repeated treatment with N-methyl-Daspartate antagonists in neonatal, but not adult, rats causes long-term deficits of radial-arm maze learning. Brain Research 2007;1169:77-86.

[22] Rujescu D, Bender A, Keck M, Hartmann AM, Ohl F, Raeder H, et al. A Pharmacological model for psychosis based on N-methyl-D-aspartate receptor hypofunction: molecular, cellular, functional and behavioral abnormalities. Biological Psychiatry 2006;59:721-9.

[23] Huang BS, Leenen FHH. Mineralocorticoid actions in the brain and hypertension. Current Hypertension Reports 2011;13:214-20.

[24] Keilhoff G, Becker A, Grecksch G, Wolf G, Bernstein HG. Repeated application of ketamine to rats induces changes in the hippocampal expression of parvalbumin, neuronal nitric oxide synthase and cFOS similar to those found in human schizophrenia. Neuroscience 2004;126:591-8.

[25] Woo TUW, Crowell AL. Targeting synapses and myelin in the prevention of schizophrenia. Schizophrenia Research 2005;73:193-207.

[26] Hatch AM, Wiberg GS, Zawidzka Z, Cann M, Airth JM, Grice HC. Isolation syndrome in the rat. Toxicology and Applied Pharmacology 1965;7:737-45.

[27] Grippo AJ, Trahanas DM, Zimmerman IIRR, Porges SW, Carter CS. Oxytocin protects against negative behavioral and autonomic consequences of longterm social isolation. Psychoneuroendocrinology 2009;34:1542-53.

[28] Grippo AJ, Lamb DG, Carter CS, Porges SW. Social isolation disrupts autonomic regulation of the heart and influences negative affective behaviors. Biological Psychiatry 2007;62:1162-70.

[29] Puglisi-Allegra S, Oliverio A. Social isolation: effects on pain threshold and stress-induced analgesia. Pharmacology Biochemistry and Behavior 1983;19:679-81.

[30] Fabricius K, Steiniger-Brach B, Helboe L, Fink-Jensen A, Wortwein G. Socially isolated rats exhibit changes in dopamine homeostasis pertinent to schizophrenia. International Journal of Developmental Neuroscience 2011;29:347-50.

[31] Fone KCF, Porkess MV. Behavioural and neurochemical effects of postweaning social isolation in rodents-relevance to developmental neuropsychiatric disorders. Neuroscience and Biobehavioral Reviews 2008;32:1087-102.

[32] Lapiz MDS, Fulford A, Muchimapura S, Mason R, Parker T, Marsden CA. Influence of postweaning social isolation in the rat on brain development, conditioned behavior, and neurotransmission. Neuroscience and Behavioral Physiology 2003;33:13-29.

[33] Fulford AJ, Marsden CA. An intact dopaminergic system is required for context-conditioned release of 5-HT in the nucleus accumbens of postweaning isolation-reared rats. Neuroscience 2007;149:392-400.

[34] Djouma E, Card K, Lodge DJ, Lawrence AJ. The CRF1 receptor antagonist, antalarmin, reverses isolation-induced up-regulation of dopamine D-2 receptors in the amygdala and nucleus accumbens of Fawn-Hooded rats. European Journal of Neuroscience 2006;23:3319-27.

[35] Hickey AJ, Reynolds JN, Beninger RJ. Post-weaning social isolation and subchronic NMDA glutamate receptor blockade: effects on locomotor activity and GABA signaling in the rat suggest independent mechanisms. Pharmacology Biochemistry and Behavior 2012;101:231-8

[36] Ashby DM, Habib D, Dringenberg HC, Reynolds JN, Beninger RJ. Subchronic MK-801 treatment and post-weaning social isolation in rats: differential effects on locomotor activity and hippocampal long-term potentiation. Behavioural Brain Research 2010;212:64-70.

[37] Becker A, Grecksch G, Zernig G, Ladstaetter E, Hiemke C, Schmitt U. Haloperidol and risperidone have specific effects on altered pain sensitivity in the ketamine model of schizophrenia. Psychopharmacology 2009;202:579-87.

[38] Becker A, Grecksch G, Schroder H. Pain sensitivity is altered in animals after subchronic ketamine treatment. Psychopharmacology 2006;189:237-47.

[39] Gibbs AG. Laboratory selection for the comparative physiologist. Journal of Experimental Biology 1999;202:2709-18.

[40] Touma C, Bunck M, Glasl L, Nussbaumer M, Palme R, Stein H, et al. Mice selected for high versus low stress reactivity: a new animal model for affective disorders. Psychoneuroendocrinology 2008;33:839-62.

[41] Smits BMG, Peters TA, Mul JD, Croes HJ, Fransen JAM, Beynon AJ, et al. Identification of a rat model for usher syndrome type $1 \mathrm{~B}$ by N-ethyl-N-nitrosourea mutagenesis-driven forward genetics. Genetics 2005;170:1887-96.

[42] Stead J, Clinton S, Neal C, Schneider J, Jama A, Miller S, et al. Selective breeding for divergence in novelty-seeking traits: heritability and enrichment in spontaneous anxiety-related behaviors. Behavior Genetics 2006;36:697-712.

[43] Dieckmann M, Freudenberg F, Klein S, Koch M, Schwabe K. Disturbed social behavior and motivation in rats selectively bred for deficient sensorimotor gating. Schizophrenia Research 2007;97:250-3.

[44] Becker A, Grecksch G. Ketamine-induced changes in rat behaviour: a possible animal model of schizophrenia. Test of predictive validity. Progress in NeuroPsychopharmacology and Biological Psychiatry 2004;28:1267-77.

[45] Barr AM, Powell SB, Markou A, Geyer MA. Iloperidone reduces sensorimotor gating deficits in pharmacological models, but not a developmental model, of disrupted prepulse inhibition in rats. Neuropharmacology 2006;51: 457-65.

[46] Ognibene E, Adriani W, Macri S, Laviola G. Neurobehavioural disorders in the infant reeler mouse model: interaction of genetic vulnerability and consequences of maternal separation. Behavioural Brain Research 2007;177: 142-9.

[47] Laviola G, Ognibene E, Romano E, Adriani W, Keller F. Gene-environment interaction during early development in the heterozygous reeler mouse: clues for modelling of major neurobehavioral syndromes. Neuroscience and Biobehavioral Reviews 2009;33:560-72.
[48] Swerdlow NR, Geyer MA, Braff DL. Neural circuit regulation of prepulse inhibition of startle in the rat: current knowledge and future challenges. Psychopharmacology 2001;156:194-215.

[49] Moriwaki M, Kishi T, Takahashi H, Hashimoto R, Kawashima K, Okochi T, et al. Prepulse inhibition of the startle response with chronic schizophrenia: a replication study. Neuroscience Research 2009;65:259-62.

[50] Ludewig K, Geyer MA, Etzensberger M, Vollenweider FX. Stability of the acoustic startle reflex, prepulse inhibition, and habituation in schizophrenia. Schizophrenia Research 2002;55:129-37.

[51] Braff DL, Geyer MA. Sensorimotor gating and schizophrenia: human and animal model studies. Archives of General Psychiatry 1990;47:181-8.

[52] Braff DL, Geyer MA, Swerdlow NR. Human studies of prepulse inhibition of startle: normal subjects, patient groups, and pharmacological studies. Psychopharmacology 2001;156:234-58.

[53] Boctor SY, Ferguson SA. Neonatal NMDA receptor antagonist treatments have no effects on prepulse inhibition of postnatal day 25 Sprague-Dawley rats. Neurotoxicology 2009;30:151-4.

[54] Takahashi M, Kakita A, Futamura T, Watanabe Y, Mizuno M, Sakimura K, et al. Sustained brain-derived neurotrophic factor up-regulation and sensorimotor gating abnormality induced by postnatal exposure to phencyclidine: comparison with adult treatment. Journal of Neurochemistry 2006;99:770-80.

[55] Su YA, Wang XD, Li JT, Guo CM, Feng Y, Yang Y, et al. Age-specific effects of early MK-801 treatment on working memory in female rats. NeuroReport 2011;22:402-6.

[56] Wedzony K, Fijal K, Mackowiak M, Chocyk A, Zajaczkowski W. Impact of postnatal blockade of $\mathrm{N}$-methyl-D-aspartate receptors on rat behavior: a search for a new developmental model of schizophrenia. Neuroscience 2008;153:1370-9.

[57] Becker A, Peters B, Schroeder H, Mann T, Huether G, Grecksch G. Ketamine-induced changes in rat behaviour: a possible animal model of schizophrenia. Progress in Neuro-Psychopharmacology and Biological Psychiatry 2003;27:687-700.

[58] Martinez ZA, Ellison GD, Geyer MA, Swerdlow NR. Effects of sustained phencyclidine exposure on sensorimotor gating of startle in rats. Neuropsychopharmacology 1999;21:28-39.

[59] Tunstall B, Beckett S, Mason R. Ultrasonic vocalisations explain unexpected effects on pre-pulse inhibition responses in rats chronically pre-treated with phencyclidine. Behavioural Brain Research 2009;202:184-91.

[60] Weiss IC, Pryce CR, Jongen-Relo AL, Nanz-Bahr NI, Feldon J. Effect of socia isolation on stress-related behavioural and neuroendocrine state in the rat. Behavioural Brain Research 2004;152:279-95.

[61] Li N, Ping J, Wu R, Wang C, Wu X, Li L. Auditory fear conditioning modulates prepulse inhibition in socially reared rats and isolation-reared rats. Behavioral Neuroscience 2008;122:107-18.

[62] Varty GB, Powell SB, Lehmann-Masten V, Buell MR, Geyer MA. Isolation rearing of mice induces deficits in prepulse inhibition of the startle response. Behavioural Brain Research 2006;169:162-7.

[63] Varty GB, Paulus MP, Braff DL, Geyer MA. Environmental enrichment and isolation rearing in the rat: effects on locomotor behavior and startle response plasticity. Biological Psychiatry 2000;47:864-73.

[64] Rosa MLNM, Silva RCB, Moura-de-Carvalho FT, Brandao ML, Guimaraes FS Del Bel EA. Routine post-weaning handling of rats prevents isolation rearinginduced deficit in prepulse inhibition. Brazilian Journal of Medical and Biological Research 2005;38:1691-6.

[65] Cilia J, Cluderay JE, Robbins MJ, Reavill C, Southam E, Kew JNC, et al. Reversal of isolation-rearing-induced PPI deficits by an alpha 7 nicotinic receptor agonist. Psychopharmacology 2005;182:214-9.

[66] Cilia J, Reavill C, Hagan JJ, Jones DNC. Long-term evaluation of isolationrearing induced prepulse inhibition deficits in rats. Psychopharmacology 2001:156:327-37.

[67] Heidbreder CA, Foxton R, Cilia J, Hughes ZA, Shah AJ, Atkins A, et al. Increased responsiveness of dopamine to atypical, but not typical antipsychotics in the medial prefrontal cortex of rats reared in isolation. Psychopharmacology 2001;156:338-51.

[68] Varty GB, Braff DL, Geyer MA. Is there a critical developmental 'window' for isolation rearing-induced changes in prepulse inhibition of the acoustic startle response? Behavioural Brain Research 1999;100:177-83.

[69] Weiss IC, Domeney AM, Moreau JL, Russig H, Feldon J. Dissociation between the effects of pre-weaning and/or post-weaning social isolation on prepulse inhibition and latent inhibition in adult Sprague-Dawley rats. Behavioural Brain Research 2001;121:207-18.

[70] Freudenberg F, Dieckmann M, Winter S, Koch M, Schwabe K. Selective breeding for deficient sensorimotor gating is accompanied by increased perseveration in rats. Neuroscience 2007;148:612-22.

[71] Hadamitzky M, Harich S, Koch M, Schwabe K. Deficient prepulse inhibition induced by selective breeding of rats can be restored by the dopamine D2 antagonist haloperidol. Behavioural Brain Research 2007;177:364-7.

[72] Schwabe K, Polikashvili N, Krauss JK. Deficient sensorimotor gating induced by selective breeding in rats is improved by entopeduncular nucleus lesions. Neurobiology of Disease 2009;34:351-6.

[73] Schwabe K, Freudenberg F, Koch $M$. Selective breeding of reduced sensorimotor gating in Wistar rats. Behavior Genetics 2007;37:706-12.

[74] Eells JB, Misler JA, Nikodem VM. Early postnatal isolation reduces dopamine levels, elevates dopamine turnover and specifically disrupts prepulse inhibition in Nurr1-null heterozygous mice. Neuroscience 2006;140: 1117-26. 
[75] Lewis DA, Cho RY, Carter CS, Eklund K, Forster S, Kelly MA, et al. Subunit-selective modulation of GABA type A receptor neurotransmission and cognition in schizophrenia. American Journal of Psychiatry 2008;165: 1585-93.

[76] Keri S, Seres I, Kelemen O, Benedek G. Neuregulin 1-stimulated phosphorylation of AKT in psychotic disorders and its relationship with neurocognitive functions. Neurochemistry International 2009;55:606-9.

[77] Schrijver NCA, Wurbel H. Early social deprivation disrupts attentional, but not affective, shifts in rats. Behavioral Neuroscience 2001;115:437-42.

[78] Dalley JD, Theobald DT, Pereira EP, Li PL, Robbins TR. Specific abnormalities in serotonin release in the prefrontal cortex of isolation-reared rats measured during behavioural performance of a task assessing visuospatial attention and impulsivity. Psychopharmacology 2002;164:329-40.

[79] McLean SL, Grayson B, Harris M, Protheroe C, Bate S, Woolley ML, et al. Isolation rearing impairs novel object recognition and attentional set shifting performance in female rats. Journal of Psychopharmacology 2010;24:57-63.

[80] Enomoto T, Floresco SB. Disruptions in spatial working memory, but not shortterm memory, induced by repeated ketamine exposure. Progress in NeuroPsychopharmacology and Biological Psychiatry 2009;33:668-75.

[81] Enomoto T, Noda Y, Nabeshima T. Phencyclidine and genetic animal models of schizophrenia developed in relation to the glutamate hypothesis. Methods and Findings in Experimental and Clinical Pharmacology 2007;29:291-301.

[82] Chatterjee M, Ganguly S, Srivastava M, Palit G. Effect of chronic versus acute ketamine administration and its withdrawal effect on behavioural alterations in mice: implications for experimental psychosis. Behavioural Brain Research 2011;216:247-54.

[83] Winters BD, Saksida LM, Bussey TJ. Implications of animal object memory research for human amnesia. Neuropsychologia 2010;48:2251-61.

[84] Ennaceur A. One-trial object recognition in rats and mice: methodological and theoretical issues. Behavioural Brain Research 2010;215:244-54.

[85] Lyon L, Saksida LM, Bussey TJ. Spontaneous object recognition and its relevance to schizophrenia: a review of findings from pharmacological, genetic, lesion and developmental rodent models. Psychopharmacology 2012;220:647-72.

[86] Winters BD, Bussey TJ. Glutamate receptors in perirhinal cortex mediate encoding, retrieval, and consolidation of object recognition memory. Journal of Neuroscience 2005;25:4243-51.

[87] Winters BD, Reid JM. A distributed cortical representation underlies crossmodal object recognition in rats. Journal of Neuroscience 2010;30:6253-61.

[88] Bianchi M, Fone KFC, Azmi N, Heidbreder CA, Hagan JJ, Marsden CA. Isolation rearing induces recognition memory deficits accompanied by cytoskeletal alterations in rat hippocampus. European Journal of Neuroscience 2006;24:2894-902.

[89] Lapiz MD, Mateo Y, Parker T, Marsden C. Effects of noradrenaline depletion in the brain on response to novelty in isolation-reared rats. Psychopharmacology 2000;152:312-20.

[90] Robbins TW, Jones GH, Wilkinson LS. Behavioural and neurochemical effects of early social deprivation in the rat. Journal of Psychopharmacology 1996;10:39-47.

[91] Hashimoto K, Fujita Y, Iyo M. Phencyclidine-induced cognitive deficits in mice are improved by subsequent subchronic administration of fluvoxamine: role of sigma-I receptors. Neuropsychopharmacology 2007;32:514-21.

[92] Hashimoto K, Fujita Y, Shimizu E, Iyo M. Phencyclidine-induced cognitive deficits in mice are improved by subsequent subchronic administration of clozapine, but not haloperidol. European Journal of Pharmacology 2005;519:114-7.

[93] Tandon R, Nasrallah HA, Keshavan MS. Schizophrenia, just the facts 4. Clinical features and conceptualization. Schizophrenia Research 2009;110:1-23.

[94] Berle J, Hauge E, Oedegaard K, Holsten F, Fasmer O. Actigraphic registration of motor activity reveals a more structured behavioural pattern in schizophrenia than in major depression. BMC Research Notes 2010;3:149.

[95] Wirz-Justice A, Haug HJ, Cajochen C. Disturbed circadian rest-activity cycles in schizophrenia patients: an effect of drugs? Schizophrenia Bulletin 2001;27:497-502.

[96] Farrow TFD, Hunter MD, Wilkinson ID, Green RD, Spence SA. Structural brain correlates of unconstrained motor activity in people with schizophrenia. British Journal of Psychiatry 2005;187:481-2.

[97] Walther S, Koschorke P, Horn H, Strik W. Objectively measured motor activity in schizophrenia challenges the validity of expert ratings. Psychiatry Research 2009;169:187-90.
[98] Walther S, Federspiel A, Horn H, Razavi N, Wiest R, Dierks T, et al. Resting state cerebral blood flow and objective motor activity reveal basal ganglia dysfunction in schizophrenia. Psychiatry Research 2011;192:117-24.

[99] Levine JB, Leeder AD, Parekkadan B, Berdichevsky Y, Rauch SL, Smoller JW, et al. Isolation rearing impairs wound healing and is associated with increased locomotion and decreased immediate early gene expression in the medial prefrontal cortex of juvenile rats. Neuroscience 2008;151:589-603.

[100] Ferdman N, Murmu RP, Bock J, Braun K, Leshem M. Weaning age, social isolation, and gender, interact to determine adult explorative and social behavior, and dendritic and spine morphology in prefrontal cortex of rats. Behavioural Brain Research 2007;180:174-82.

[101] Paulus MP, Varty GB, Geyer MA. The genetic liability to stress and postweaning isolation have a competitive influence on behavioral organization in rats. Physiology and Behavior 2000;68:389-94.

[102] Gentsch C, Lichtsteiner M, Frischknecht HR, Feer H, Siegfried B. Isolationinduced locomotor hyperactivity and hypoalgesia in rats are prevented by handling and reversed by resocialization. Physiology and Behavior 1988;43:13-6.

[103] Bakshi VP, Geyer MA. Ontogeny of isolation rearing-induced deficits in sensorimotor gating in rats. Physiology and Behavior 1999;67:385-92.

[104] Meng Q, Li N, Han X, Shao F, Wang W. Peri-adolescence isolation rearing alters social behavior and nociception in rats. Neuroscience Letters 2010;480:25-9.

[105] Farber NB, Wozniak DF, Price MT, Labruyere J, Huss J, St.Peter H. Age-specific neurotoxicity in the rat associated with NMDA receptor blockade: potential relevance to schizophrenia? Biological Psychiatry 1995;38:788-96.

[106] Simpson SM, Menard JL, Reynolds JN, Beninger RJ. Post-weaning social isolation increases activity in a novel environment but decreases defensive burying and subchronic MK-801 enhances the activity but not the burying effect in rats. Pharmacology Biochemistry and Behavior 2010;95:72-9.

[107] Gandal MJ, Anderson RL, Billingslea EN, Carlson GC, Roberts TPL, Siegel SJ. Mice with reduced NMDA receptor expression: more consistent with autism than schizophrenia? Genes, Brain and Behavior 2012;11:740-50.

[108] Hart PC, Bergner CL, Smolinsky AN, Dufour BD, Egan RJ, LaPorte JL, et al. Experimental models of anxiety for drug discovery and brain research. Methods in Molecular Biology 2010;602:299-321.

[109] Audet MC, Goulet S, Dore FY. Repeated subchronic exposure to phencyclidine elicits excessive atypical grooming in rats. Behavioural Brain Research 2006;167:103-10.

[110] Clark BJ, Hines DJ, Hamilton DA, Whishaw IQ. Movements of exploration intact in rats with hippocampal lesions. Behavioural Brain Research 2005;163:91-9.

[111] Jochum T, Letzsch A, Greiner W, Wagner G, Sauer H, Bar KJ. Influence of antipsychotic medication on pain perception in schizophrenia. Psychiatry Research 2006;142:151-6.

[112] Dworkin RH. Pain insensitivity in schizophrenia: a neglected phenomenon and some implications. Schizophrenia Bulletin 1994;20:235-48.

[113] Tuboly G, Horvath G. Pain sensitivity changes in patients and animal models. Part I. Ideggyogyaszati Szemle-Clinical Neuroscience 2009;62:4-11.

[114] Van den Berg CL, Van Ree JM, Spruijt BM, Kitchen I. Effects of juvenile isolation and morphine treatment on social interactions and opioid receptors in adult rats: behavioural and autoradiographic studies. European Journal of Neuroscience 1999;11:3023-32.

[115] Szikszay M, Benedek G. Tolerance to morphine induced by chronic mild environmental stressors. Acta Physiologica Hungarica 1989;73:447-53.

[116] DeFeudis FV, Defeudis PA, Somoza E. Altered analgesic responses to morphine in differentially housed mice. Psychopharmacology 1976;49:117-8.

[117] Tuboly G, Horvath G. Pain sensitivity changes in schizophrenic patients and animal models, Part II. Ideggyogyaszati Szemle-Clinical Neuroscience 2009;62:148-53.

[118] Coid J, Yang M. The distribution of psychopathy among a household population: categorical or dimensional? Social Psychiatry and Psychiatric Epidemiology 2008;43:773-81.

[119] Tryon RC. The genetics of learning ability in rats - a preliminary report. University of California Publications in Psychology 1929;4:71-85.

[120] Viggiano D, Vallone D, Welzl H, Sadile AG. The Naples high- and lowexcitability rats: selective breeding, behavioral profile, morphometry, and molecular biology of the mesocortical dopamine system. Behavior Genetics 2002;32:315-33.

[121] Toulopoulou T, Goldberg TE, Mesa IR, Picchioni M, Rijsdijk F, Stahl D, et al. Impaired intellect and memory: a missing link between genetic risk and schizophrenia? Archives of General Psychiatry 2010;67:905-13. 